\title{
Ideologia e partidos políticos: um estudo sobre coligações em Santa Catarina'
}

\author{
Yan de Souza Carreirão \\ Universidade Federal de Santa Catarina
}

\begin{abstract}
Resumo
O trabalho analisa os padrões ideológicos das coligações realizadas nas eleições para governador, deputado federal, deputado estadual e prefeito, no período 1986/2004, em Santa Catarina. O objetivo principal é o de verificar em que medida a ideologia constitui um obstáculo à realização de coligações "inconsistentes" e se há mudança nos padrões de coligação ao longo do período. A análise revela que no início da vigência do atual sistema partidário a proporção de coligações ideologicamente inconsistentes era pequena em relação ao conjunto das candidaturas lançadas. Ao longo do tempo o número deste tipo de coligação cresce, particularmente nas duas últimas eleições.
\end{abstract}

Palavras-chave: coligações eleitorais, partidos políticos, ideologia, política estadual

\begin{abstract}
This article analyses the ideological patterns of coalitions performed at the elections for governor, federal representative, state representative and mayor, between 1986 and 2004, in Santa Catarina. The main goal is to verify to what extent ideology constitutes an obstacle to the making of "inconsistent" coalitions and if there are changes in the coalitions patterns, along the period at study. The analysis reveals that at the beginning of the operation of the current party system the proportion of ideologically inconsistent coalitions was small, in relation to the candidatures as a whole. As time passed by, however, the proportion of ideologically inconsistent coalitions increased substantially.
\end{abstract}

Key words: electoral coalitions, political parties, ideology, state politics

1 Este trabalho é fruto de pesquisa que obteve financiamentos, em 2004, do Funpesquisa (UFSC) e, em 2005, do Conselho Nacional de Desenvolvimento Científico e Tecnológico (CNPq), entidade governamental brasileira promotora do desenvolvimento científico e tecnológico. 
A literatura brasileira recente tem discutido, em âmbito nacional, em que medida as diferenças ideológicas supostas entre os partidos se manifestam efetivamente em opiniões e ações (coligações eleitorais, coalizões de governo, políticas públicas etc.) dos membros dos diversos partidos. A produção sobre o tema em âmbito estadual, porém, é escassa. $O$ presente trabalho pretende contribuir para minimizar esta deficiência, a partir da análise dos padrões ideológicos das coligações realizadas nas eleições para governador, deputado federal, deputado estadual e prefeito, no período 1986/2004, em Santa Catarina. Embora do ponto de vista teórico-metodológico o ideal fosse realizar um trabalho comparativo, envolvendo diferentes unidades da federação, isto não foi possível nos limites desta pesquisa. De toda forma, espera-se que a análise represente uma reflexão significativa sobre o tema e que, à medida que outros estudos semelhantes forem realizados em outros estados, análises comparativas mais amplas possam ser realizadas.

O objetivo principal é o de verificar em que medida a ideologia constitui (ou não) um obstáculo à realização de coligações "inconsistentes" e se há mudança nos padrões de coligação, ao longo do período estudado. Inicialmente a utilização do continuum direita-esquerda como referencial para análise é justificada; em seguida são apresentadas as principais teses sobre coligações na literatura brasileira; na terceira seção são analisados os padrões das coligações mencionadas acima; a quarta seção apresenta uma análise do rendimento das diferentes estratégias eleitorais e, por fim, as considerações finais apontam hipóteses explicativas para os padrões encontrados.

\section{0 continuum direita-esquerda como referencial para análise ${ }^{2}$}

O tema das ideologias partidárias é tratado de forma variada na literatura, e nesse âmbito o continuum direita-esquerda está privilegiado como referencial de análise neste trabalho. Na verdade, o uso deste material para análise da ação dos partidos políticos é muitas vezes visto como inadequado ou inútil, especialmente pelos meios de comunicação, que consideram os partidos políticos brasileiros

\footnotetext{
2 Parte da argumentação apresentada em algumas seções deste artigo é fruto de trabalho sobre o tema, realizado em conjunto com Marta Zorzal e Silva e Denise Paiva, a quem agradeço pela permissão para utilisar certos trechos aqui. Agradeço também às estudantes Lígia Granado Rodrigues e Sibeli Dassoler, que colaboraram na coleta e análise dos dados. Por fim, meus agradecimentos aos pareceristas anônimos, cujas sugestões foram consideradas, na medida de minhas possibilidades.
} 
indiferenciados ideologicamente ${ }^{3}$. Este diagnóstico aponta como alguns dos seus indícios a ocorrência de coligações eleitorais ou coalizões governamentais "esdrúxulas", que envolvem simultaneamente partidos, formalmente situados, à direita e à esquerda do espectro ideológico, e a alta taxa de migração de políticos entre partidos.

As posições adotadas pelo governo Lula e os fatos relacionados à crise política que se deflagrou a partir de maio de 2005 em torno das denúncias que desembocaram nas Comissões Parlamentares de Inquérito dos Correios e do "Mensalão", além da dos Bingos, reforçaram ainda mais a tese da indiferenciação entre os partidos brasileiros nos meios de comunicação.

Sem pretender discutir de forma aprofundada o tema da diferenciação ideológica, do ponto de vista teórico ${ }^{4}$, o que nos interessa aqui é que muitos estudos feitos pela ciência política brasileira, de cerca de dez anos para cá, utilizaram a classificação dos partidos num eixo direita-esquerda, tendo mostrado um bom rendimento deste referencial para a análise da atuação dos partidos. Assim, por exemplo, Kinzo (1993) no início dos anos noventa, afirma que, ao nível nacional:

"pelo menos os partidos mais importantes, como PMDB, PFL, PSDB, PPR, PT, PDT e PTB, têm tomado posições diferenciadas, e seus posicionamentos têm manifestado razoável continuidade, indicando uma possível fixação de seus perfis. Embora a coesão interna ainda seja precária na maioria dos partidos e apesar da forte fragmentação que caracteriza o sistema partidário, já existem alguns condutos ou espaços ideológico-partidários capazes de balizar a luta político-eleitoral" (KINZO, 1993, p. 96).

Figueiredo e Limongi (1999), analisando dados relativos ao período 1989/94, apresentam dados que colocaram em questão a tese dominante até meados da década de 1990 , de que a indisciplina seria o padrão na votação dos deputados no plenário da Câmara, marcado pela votação segundo seus interesses pessoais, desconsiderando os apelos das lideranças. Se este fosse realmente o padrão, postular diferenças de comportamento nas votações entre partidos de esquerda e direita não teria o menor sentido. Os dados de Figueiredo e Limongi

\footnotetext{
3 Apenas para dar um exemplo recente: "o núcleo ideológico-social de PSDB, PT e PFL é pequeno. Inflam ou desinflam de acordo com a oportunidade de poder que oferecem. Quem não se adapta fica no PMDB e nos satélites do mercado de varejo político. (...) Os partidos são regionais, caciquistas e clientes do Estado. (...) Se o sistema partidário é uma geléia, a causa não é formal, legal. Entre outros tantos motivos, o sistema não tem espinha por faltar um partido popular de verdade" (FREIRE, 2005).

4 Para uma discussão mais abrangente a respeito do uso destes termos, ver Castañeda (1994), Bobbio (1995) e Fernandes (1995), entre outros.
} 
mostram que há taxas bastante razoáveis de disciplina partidária ${ }^{5}$. Além disso, o que é mais importante para os propósitos deste trabalho, mostraram que nas votações na Câmara dos Deputados as coalizões seguem os posicionamentos dos partidos numa escala esquerda-direita:

"Os partidos apresentaram considerável coesão média no período como um todo. (...) O quadro que emerge da análise revela um padrão de coalizões partidárias que é coerente com a disposição dos partidos num continuum ideológico. Podemos falar tranqüilamente em partidos de direita, de centro e de esquerda" (FIGUEIREDO e LIMONGI, 1999, p. 75).

No âmbito da composição social das elites partidárias, Rodrigues (2002) mostra diferenças também significativas no que respeita às profissões, às ocupações e ao patrimônio dos deputados federais dos diferentes partidos.

No que respeita à visualização dos partidos numa escala esquerda-direita por parte dos eleitores, Singer (2000) pleiteia que, mesmo não tendo uma compreensão clara dos significados das noções de esquerda e direita, boa parte do eleitorado consegue, intuitivamente, localizar os partidos nesta dimensão e votar em acordo com esta localização6.

A exposição das referências acima visa apenas apontar que há um conjunto de estudos que pleiteia a pertinência do uso do continuum esquerda-direita como uma forma possível de mapear o campo político-partidário brasileiro atual, estabelecendo semelhanças entre certos grupos de partidos entre si e diferenças com outros grupos de partidos. Esse tipo de diferenciação permite compreender tanto certos elementos da tomada de decisão do eleitorado quanto diferenças de opinião e de comportamento efetivo entre políticos de diferentes partidos. A seção seguinte apresenta estudos que abordam a questão da coligação.

\footnotetext{
5 Nicolau (2000), analisando dados relativos ao período 1995/98, embora matize um pouco as conclusões tiradas por aqueles autores, no que respeita à disciplina partidária, também não vai endossar a tese da indisciplina partidária generalizada na Câmara dos Deputados.Para uma visão crítica quanto as teses de Figueiredo e Limongi, ver Ames (2003) e Mainwaring (2001). Melo (2004), a partir da análise das migrações partidárias, propõe diferenciar disciplina e coesão partidárias. Vale a pena mencionar que as denúncias de compra de votos, no chamado "escândalo do mensalão", adicionam um ingrediente a mais na possível explicação das taxas de disciplina relativamente altas na Câmara Federal, além dos fatores apontados por aqueles autores (entre os quais destacam-se as prerrogativas legais e os recursos patrimonialistas do presidente no processo legislativo, além da influência dos líderes partidários).

6 Visões críticas às teses de Singer são apresentadas em Reis (2002) e Carreirão (2002).
} 


\section{As teses sobre coligações na literatura brasileira}

Diferentes preocupações têm marcado o debate na literatura brasileira sobre coligações, seja no período entre 1946 e 1964, seja no período relativo ao atual sistema partidário.

Algumas das discussões abordam os possíveis impactos das coligações sobre a fragmentação do sistema partidário e a representatividade do sistema político, especialmente no que se refere a possíveis distorções de representação na Câmara Federal (SOUZA, 1976; SANTOS, 1987; NICOLAU, 1996; TAVARES, 1998, dentre outros). Não é esta a preocupação do presente trabalho.

Outra questão fundamental é a das motivações dos partidos ao realizar as coligações. Quanto a isso, há consenso na literatura de que o objetivo mais geral das coligações é ampliar as chances eleitorais dos partidos, e de que a decisão estratégica sobre coligações é tomada com base em um cálculo de custos e benefícios eleitorais (SOUZA, 1976; LIMA JÚNIOR, 1983; SANTOS, 1987; FIGUEIREDO, 1994; NICOLAU, 1994) ${ }^{7}$.

Embora aceitando esta tese, a questão central do presente trabalho é: o posicionamento ideológico dos partidos entra no cálculo dos custos e benefícios eleitorais como um custo relevante, que poderia inibir a participação em coligações ideologicamente inconsistentes? A hipótese inicial é a de que o posicionamento ideológico do partido - seja pelo seu programa, pelas declarações de seus líderes, seja pelo comportamento dos seus detentores de mandatos públicos - repercute na opinião pública e forma uma imagem junto ao eleitorado que pode atuar como uma limitação ao padrão ideológico de coligação "permitido" ao partido. Realizar coligações fora de um padrão minimamente esperado do partido pode ter custos político-eleitorais futuros. Além disso, pode haver graus diferenciados de "nitidez ideológica" das imagens partidárias formadas pelos eleitores, o que faria com que os custos de uma eventual coligação com um partido de outro campo ideológico

\footnotetext{
7 Se a orientação geral é esta, as motivações específicas são variadas: assim, nos pleitos proporcionais, os pequenos partidos visam escapar do quociente eleitoral, coligando-se com partidos maiores. Estes últimos podem ter interesse em se coligar com os pequenos nas eleições majoritárias - vinculando-se, assim, muitas vezes as coligações nos dois tipos de pleitos -, seja para evitar que estes últimos se coliguem com outros partidos, seja para ampliar seu tempo no horário eleitoral gratuito, seja ainda para ampliar o número de candidatos (acomodando, assim, disputas internas ao partido). Uma hipótese interessante, formulada a partir da análise do período 1945/64, é a de Lima Jr., de que as coligações seguem uma "estratégia de racionalidade política contextual: as decisões partidárias de formar alianças foram racionais porque tinham como principal objetivo maximizar o apoio eleitoral e foram contextuais porque tomadas localmente, à luz dos resultados da eleição prévia e não de acordo com uma estratégia partidária nacional" (LIMA Jr., 1983, p. 76-77).
} 
sejam variáveis para diferentes partidos $^{8}$. São estas questões e hipóteses que norteiam a presente investigação.

Para o período entre 1945 e 1964, um dos estudos importantes que enfrenta tais questões é o de Soares (1964) que, analisando coligações para a Câmara Federal conclui que, pelo menos nas regiões mais desenvolvidas do país, "os partidos com bases classistas não podem coligar-se impunemente com partidos representantes de classes sociais antagônicas", já que:

"tanto para atrair, quanto para manter a atração com relação a determinada classe social, um partido tem que funcionar como representante dessa classe. Os desvios dessa função são punidos com a perda de grande parte do eleitorado" (SOARES, 1964, p. 107).

A quase totalidade da literatura sobre aquele período ${ }^{9}$, no entanto, minimiza o posicionamento ideológico dos partidos como variável relevante na explicação das coligações. Santos (1987), particularmente, dividindo os partidos do período em dois grupos (progressistas e conservadores) e analisando as coligações para a Câmara Federal entre 1950 e 1962, conclui que:

"a porcentagem de alianças inconsistentes aumenta ao longo do período, à exceção de 1962, quando retornou aos valores de 1950, mas ainda assim superior a $50 \%$ do número total de coligações (...) A dinâmica das coligações obedeceria, assim, ao objetivo de maximizar votos, nas circunstâncias dadas, idiossincrasias estaduais também levadas em consideração" (SANTOS, 1987, p. 108).

Com variações, essa é a tônica dos trabalhos sobre aquele período. No que se refere ao período atual, Figueiredo (1994), analisando coligações feitas em âmbito estadual, nas eleições de 1994, conclui que os partidos decidem sua estratégia de coligações a partir de um cálculo de custos e benefícios eleitorais, em que, mantidos os benefícios constantes, procuram aliados à sua direita ou à sua esquerda em função de sua base eleitoral (outras alegações não indo além da pura

\footnotetext{
8 Note-se, porém, que não é necessário, para admitir constrangimentos ideológicos à realização de coligações, aceitar a hipótese de que a maioria do eleitorado reconheça inconsistências e puna os partidos. É possível admitir aqueles constrangimentos a partir, por exemplo, da formulação bem mais geral de Panebianco (1988), de que partidos precisam distribuir não só incentivos seletivos, mas também coletivos (relacionados à "identidade" e à "ideologia" do partido), para que seus "membros" simpatizantes, filiados, militantes, dirigentes - participem politicamente. Ou seja, pode haver um custo político à realização de coligações inconsistentes, pela perda de membros de um partido (e não só pela perda de eleitores).

9 Schwartzman (1971), Souza (1976), Lima Jr. (1983), Santos (1987), dentre outros.
} 
retórica eleitoral). Ao longo do texto, o autor, porém, atenua esta afirmação, fazendo a ressalva de que uma grande distância ideológica entre dois partidos pode agir como um obstáculo a coligações entre eles.

Nicolau, analisando as mesmas eleições, conclui que: "os partidos de esquerda se coligam preferencialmente e em casos excepcionais com os da direita" (NICOLAU, 1994, p. 16). E ainda:

"o PT foi o único entre os grandes partidos a estabelecer uma política nacional de coligações, com sua direção vetando e estimulando diversas alianças regionais. O PT disputará os governos estaduais em todos os estados. Em 17 deles está encabeçando coligações à esquerda, em dois com candidatos únicos e em oito apoiando candidatos alheios (um do PSDB, três do PSB e quatro do PDT)" (NICOLAU, 1994, p. 18).

Novaes (1994) afirma que:

"no período eleitoral, as cúpulas partidárias promovem as coligações no intuito de incrementar suas próprias chances de sucesso. (...) Esse cálculo preside a formação das coligações, que se orientam regionalmente pelas afinidades ideológicas clássicas, que por sua vez, resultam de alinhamentos feitos segundo interesses" (NOVAES, 1994, p. 113).

Assim, o autor afirma que o caráter estratégico das coligações não significa que elas ocorram desconsiderando certos limites ideológicos.

Schmitt (1999), mostra que, das coligações eleitorais realizadas entre 1986 e 1994 na Câmara dos Deputados, 16\% seriam coligações ideologicamente inconsistentes (ou seja, envolvendo simultaneamente partidos de direita e de esquerda), contra $66 \%$ de coligações consistentes (envolvendo apenas partidos do mesmo campo ideológico) e $18 \%$ de coligações envolvendo partidos de centro com partidos de direita ou de esquerda. O padrão, portanto, não revela um quadro de completa "mistura" de partidos, apontado pelo diagnóstico impressionista predominante nos meios de comunicação.

Em conclusão, embora vários estudos apontem um certo peso do posicionamento ideológico dos partidos em relação às decisões sobre coligações eleitorais, não há na literatura um consenso sobre isso. São necessários mais estudos empíricos sobre os diversos cargos e níveis (municipal, estadual e federal) para que se possa ter uma compreensão maior do fenômeno. A intenção aqui é a de trazer evidências que possam contribuir para o debate sobre o tema. 


\section{Padrões de coligações nas eleições em Santa Catarina $(1986 / 2004)^{10}$}

Com base na literatura mencionada acima e especialmente nas classificações formuladas nos estudos de Kinzo (1990), Novaes (1994), Figueiredo e Limongi (1999), Fernandes (1995) e Rodrigues (2002), tomo como definição operacional inicial a seguinte classificação dos partidos no Brasil, no eixo direita-esquerda:

- $\quad$ Direita: PP (PPB; PPR; PDS) ${ }^{11}$; PFL; PRN; PDC; PL; PTB; PSC; PSP; PRP; PSL; PSD e PRONA.

- Centro: PMDB e PSDB.

- Esquerda: PT; PDT; PPS; PCdoB; PSB; PV; PSTU; PCO e PMN12.

Foram considerados como "indefinidos" ideologicamente por insuficiência de informações, os demais partidos (PST, PHS, PTC, PTdoB, PRTB, PSDC e PAN). De qualquer forma, o peso político-eleitoral desses partidos, especialmente em Santa Catarina, é quase nulo. Vale a pena indicar que, grosso modo, as posições dos partidos em Santa Catarina num continuum direita-esquerda é semelhante à dos partidos em âmbito nacional, o que justifica a utilização da classificação predominante na literatura nacional ${ }^{13}$. Uma exceção, talvez, seja o PSDB, que até 1994 tinha em Santa Catarina um perfil mais à esquerda do que o perfil médio nacional do partido.

Os padrões de coligações entre os partidos catarinenses nos pleitos para governador e prefeito estão analisados segundo uma ótica que privilegia o seu "grau

10 Não foram consideradas as eleições de 1982, por estas terem sido eleições em que as coligações foram proibidas.

11 Partido Progressista é o atual nome de uma organização partidária que vem mudando de sigla (eventualmente com a incorporação ou fusão de outras legendas) e cuja origem é o Partido Democrático Social (PDS), surgido em 1980 como sucessor da antiga ARENA. Em 1993, o PDS incorporou o Partido Democrata Cristão, mudando seu nome para Partido Progressista Reformador (PPR), que participou do pleito de 1994. Com a incorporação do Partido Progressista (PP), em 1995, surge o PPB (Partido Progressista Brasileiro). Em 2003, o PPB, avaliando o desgaste da sigla, em âmbito nacional, resolve mudar novamente de nome, adotando o atual (Partido Progressista - PP). Embora em cada eleição a sigla tenha sido diferente, a referência aqui será sempre à sigla PP.

12 Alguns autores (como Figueiredo e Limongi, 1999) optam por classificações com mais duas posições: centro-esquerda e centro-direita. A maioria dos autores, entretanto, tem trabalhado com uma classificação mais simplificada, com três posições, que nos parece suficiente para os propósitos deste trabalho (embora uma classificação com 5 posições pudesse levar a conclusões um tanto diferentes das aqui encontradas).

13 Um indício empírico desta semelhança é que deputados estaduais catarinenses, quando instados a posicionar os diferentes partidos numa escala esquerda-direita, o fazem de forma muito parecida com avaliação semelhante feita por deputados estaduais de todo o país (conforme dados de duas pesquisas, coordenadas em 1989 e 2001 por Maria D'Alva Kinzo em âmbito nacional e pelo autor em Santa Catarina). 
de coerência ideológica". A partir da classificação partidária estabelecida acima, foram definidos "graus de coerência ideológica" das coligações, de forma a operacionalizar a análise, quais sejam:

a) Forte: quando a coligação se dá apenas entre partidos situados em um mesmo "campo" do espectro político - esquerda (E), centro (C) ou direita (D). As possibilidades de coligação nesse caso são: D-D; C-C; E-E.

b) Médio: quando a coligação envolve partidos de centro com partidos de esquerda ou com partidos de direita. As possibilidades são: C-D; C-E.

c) Fraco: quando a coligação envolver partidos de pólos extremos (direita e esquerda). As possibilidades são: D-E; D-C.E 14 .

\section{Padrões de coligação nas eleições para governador}

A Tabela 1 faz a classificação das candidaturas apresentadas nas eleições para governador entre 1986 e 2004, diferenciando as candidaturas isoladas das coligações e classificando estas últimas segundo o seu "grau de coerência ideológica"15.

14 Duas observações a respeito dessa classificação são importantes:

a) Não importa, para os propósitos deste trabalho, o número de partidos de cada "campo" envolvidos na coligação. Assim, por exemplo, tanto a coligação PT/PDT/PCdoB/PSB/PL, quanto a coligação PDT/PP são classificadas como sendo inconsistentes.

b) Os partidos considerados como "indefinidos" são desconsiderados na classificação das coligações (que serão classificadas de acordo com os demais partidos que compõem a coligação). Esta decisão implica numa subestimação das coligações com graus fraco e médio de coerência ideológica e uma superestimação das coligações com grau forte de coerência ideológica. Apesar disso, esta escolha foi feita porque: i) a proporção de casos que envolvem partidos "indefinidos" não é muito significativa; ii) boa parte das coligações que envolvem estes partidos reúnem vários partidos (tendo o "indefinido" pouco peso no conjunto da coligação); iii) os partidos considerados "indefinidos" são eleitoralmente pouco significativos (apenas em 2004 PTC e PST elegeram alguns vereadores; em todas as outras eleições, para todos os outros cargos, nenhum partido "indefinido" elegeu qualquer representante, em Santa Catarina) ; iv) do ponto de vista que aqui interessa, estas distorções são pouco relevantes. Isso porque a probabilidade de que um partido deixe de fazer uma coligação inconsistente por receio de ser punido pelo eleitor parece ser relevante apenas no caso dos partidos terem uma "identificação ideológica" clara. Se não há nem na literatura clareza quanto à classificação destes pequenos partidos, deve-se esperar que menos ainda o eleitor mediano identifique a ideologia destes partidos e, portanto, a coerência (ou não) da coligação em que estes partidos participem.

15 Os percentuais são calculados sobre o número total de candidaturas, incluindo as isoladas, porque estas últimas correspondem a uma estratégia que supõe-se ter repercussões positivas, em termos da percepção que o eleitorado tem do grau de "consistência ideológica" dos partidos e do sistema partidário. Se, por exemplo, de 100 candidaturas lançadas, 90 são candidaturas isoladas e 10 são em coligações, das quais 7 são inconsistentes, estas últimas representarão $70 \%$ das coligações, mas apenas $7 \%$ do conjunto das candidaturas lançadas. A impressão que o eleitorado formaria do sistema partidário, a partir do conjunto das candidaturas, não deveria ser a de uma "geléia geral" - contrastando com uma impressão que poderíamos ter, se nos restringíssemos a calcular a proporção de coligações sobre o 
Tabela 1

Número de coligações nas eleições para governador, segundo grau de coerência ideológica (Santa Catarina 1986-2002)

\begin{tabular}{|c|c|c|c|c|c|c|}
\hline \multirow{2}{*}{ Ano } & \multicolumn{2}{|c|}{ Grau de Coerência Ideológica } & \multirow{2}{*}{$\begin{array}{c}\text { Total } \\
\text { Coligações }\end{array}$} & $\begin{array}{c}\text { Total } \\
\text { Candidaturas } \\
\text { Isoladas }\end{array}$ & $\begin{array}{c}\text { Total Geral } \\
\text { Candidaturas }\end{array}$ \\
\cline { 2 - 4 } & FORTE & MÉDIO & FRACO & & 4 & 5 \\
\hline 1986 & 1 & 0 & 0 & 1 & 4 & 6 \\
\hline 1990 & 2 & 0 & 0 & 2 & 2 & 4 \\
\hline 1994 & 0 & 1 & 1 & 2 & 4 & 6 \\
\hline 2002 & 1 & 1 & 0 & 2 & 1 & 5 \\
\hline Total (N) & 2 & 0 & 2 & 4 & 15 & 26 \\
\hline Total (\%) & 23,1 & 7,7 & 11,5 & 42,3 & 57,7 & 100,0 \\
\hline
\end{tabular}

Fonte: TRE/SC

No período analisado apenas 11 das 26 candidaturas lançadas nas cinco eleições para governador em Santa Catarina foram em coligações, e destas, 6 foram entre partidos do mesmo "campo ideológico"16. Se somarmos as candidaturas isoladas e as coligações mais consistentes ideologicamente, teremos cerca de $81 \%$ das candidaturas a governador lançadas em todo o período, contra $11,5 \%$ de candidaturas mais inconsistentes e $7,5 \%$ de grau médio de consistência ideológica.

A análise revela que, em 1994, uma das candidaturas de "grau médio de coerência ideológica" envolveu cinco partidos de esquerda além do PSDB que, em Santa Catarina, havia definido um perfil mais à esquerda que a média nacional do partido, tendo sido inclusive uma das principais resistências à coligação com o PFL na eleição presidencial daquele ano. A outra ocorreu em 1998, envolvendo também - PSDB e um grande número de partidos, sendo a grande maioria composta de partidos situados claramente à direita (PDS, PFL, PTB, PRN) e outros pequenos partidos não classificados na literatura nacional, ou classificados à direita. Das três candidaturas mais "inconsistentes" (ou de "grau fraco de coerência ideológica"), a primeira definiu-se em 1994 entre o PMDB e pequenos partidos de direita além do PV (considerado aqui como de esquerda). Na realidade tratou-se de uma

número de coligações (neste caso, 70\%). Para uma visualização qualitativa das coligações realizadas nas eleições para o governo do Estado, ver Anexo 1.

16 Deve-se considerar aqui a ressalva já feita quanto ao fato de que alguns dos pequenos partidos não classificados no espectro ideológico pela literatura nacional não foram considerados para classificar as coligações. 
candidatura percebida de forma generalizada como peemedebista, mas que, no entanto, segundo nossos critérios se enquadra como "inconsistente". As outras duas candidaturas ocorreram em 2002: uma ocorreu entre o PSB e o PSD, dois partidos minúsculos em Santa Catarina, sendo um classificado à esquerda e o outro à direita e a outra ocorreu entre o PT e mais dois partidos de esquerda, além do PL.

Na realidade, das candidaturas relevantes, boa parte foi constituída por um bloco à direita formado pelo PP (PDS/PPR/PPB) e o PFL (houve vezes em que os dois partidos saíram separados) e outros pequenos partidos; um bloco ao centro, capitaneado pelo $\mathrm{PMDB}$, com pequenos partidos coligados, e um terceiro bloco à esquerda, reunindo o PT, o PDT, o PPS, o PCdoB e outros partidos menores. Assim, considerando apenas as coligações no $1^{\circ}$ turno, há um padrão de relativamente alta consistência ideológica nas eleições para governador.

\section{Padrões de coligações nas eleições para prefeito}

A Tabela 2, abaixo, nos mostra o conjunto de candidaturas para prefeito em todos os municípios de Santa Catarina entre 1988 e 2004.

Tabela 2

Grau de coerência ideológica das coligações nas eleições para prefeito (Santa Catarina 1988-2004) (\%)

\begin{tabular}{|c|c|c|c|c|c|c|}
\hline \multirow{2}{*}{ Ano } & \multicolumn{3}{|c|}{ Grau de Coerência Ideológica } & \multirow{2}{*}{$\begin{array}{l}\text { Total } \\
\text { Coligações } \\
\text { (\%) }\end{array}$} & \multirow{2}{*}{$\begin{array}{c}\text { Total } \\
\text { Candidaturas } \\
\text { Isoladas (\%) }\end{array}$} & \multirow{2}{*}{$\begin{array}{c}\text { Total Geral } \\
\text { Candidaturas } \\
\text { (N) }\end{array}$} \\
\hline & FORTE (\%) & MÉDIO (\%) & FRACO (\%) & & & \\
\hline 1988 & 19,0 & 8,0 & 5,0 & 32,0 & 68,0 & 568 \\
\hline 1992 & 26,0 & 25,0 & 10,0 & 61,0 & 39,0 & 637 \\
\hline 1996 & 18,9 & 30,0 & 17,0 & 66,0 & 34,0 & 692 \\
\hline 2000 & 21,0 & 29,6 & 16,3 & 66,6 & 33,4 & 742 \\
\hline 2004 & 13,0 & 31,0 & 29,0 & 73,0 & 27,0 & 751 \\
\hline TOTAL [N] & 662 & 866 & 541 & 2069 & 1321 & 3390 \\
\hline TOTAL [\%] & 20,0 & 25,0 & 16,0 & 61,0 & 39,0 & 100,0 \\
\hline
\end{tabular}

Fonte: TRE/SC.

Obs.: Percentuais somam $100 \%$ nas linhas. 
Considerando o conjunto das cinco eleições para prefeito ocorridas no período, tivemos no estado 3.390 candidaturas. Destas, 39\% foram candidaturas isoladas e $61 \%$ candidaturas coligadas. Se somarmos as coligações ideologicamente mais "consistentes" com as candidaturas isoladas, teremos cerca de $60 \%$ do total de candidaturas do período. Apenas $16 \%$ das candidaturas são de coligações ideologicamente mais "inconsistentes", ou seja, envolvendo partidos de esquerda e de direita, simultaneamente. Finalmente, $25 \%$ são coligações que envolvem partidos de centro, ora com partidos de esquerda (11\%), ora com partidos de direita (14\%).

Algumas tendências se desenvolveram ao longo do período. Em primeiro lugar, houve um aumento da proporção de coligações em relação ao total das candidaturas: das candidaturas lançadas em 1988, apenas 32\% foram em coligações; este percentual subiu para $73 \%$ em 2000. Em segundo lugar, cresceu o grau de inconsistência ideológica das coligações. Em 1988 havia um forte grau de coerência ideológica nas eleições para prefeito: apenas $5 \%$ eram coligações mais inconsistentes e $8 \%$ tinham um "grau médio de coerência ideológica". Portanto, somando estes dois tipos de coligações, tivemos $13 \%$ das candidaturas em 1988, contra 60\% em 2004. Inversamente, 87\% das candidaturas em 1988 foram isoladas ou em coligações ideologicamente consistentes; este percentual caiu para 40\% em 2004.

Concluindo, o quadro mais geral que se visualiza mostra: por um lado, que, de fato, não há uma coerência ideológica total nas coligações realizadas. De outro lado, as coligações realizadas não permitem pleitear a existência de um grande caos partidário tal qual visualizado por grande parte da mídia. Se considerarmos que coligações que não envolvam simultaneamente partidos de esquerda e partidos de direita não provocam tanta rejeição, ficamos com um percentual médio, no período, de $16 \%$ coligações inconsistentes nas eleições para prefeito. Mas, um dado bastante relevante é o de que o grau de inconsistência é crescente. Isso será retomado mais adiante.

\section{As coligações nas eleições proporcionais}

A Tabela 3 apresenta os dados sobre candidaturas nas eleições para deputado federal e deputado estadual em Santa Catarina, entre 1986 e $2004{ }^{17}$.

\footnotetext{
17 Candidatura isolada, na tabela, significa que um partido lançou uma lista de candidatos, sem coligação com outros partidos. Embora em eleições proporcionais o número de candidatos seja, evidentemente, muito maior, será tratado aqui, para os propósitos de nosso estudo, como número de "candidaturas", o número de partidos ou coligações que lançaram listas de candidatos a estas eleições.
} 
OPINIÃO PÚBLICA, Campinas, vol. 12, no 1, Abril/Maio, 2006, p. 136-163

Tabela 3

Tipos de candidaturas nas eleições proporcionais

(Deputados federais e estaduais - Santa Catarina 1986-2002) (N)

\begin{tabular}{|c|c|c|c|c|c|c|c|}
\hline \multirow{2}{*}{ Cargo } & \multirow{2}{*}{ Ano } & \multicolumn{3}{|c|}{ Grau de Coerência Ideológica } & \multirow{2}{*}{$\begin{array}{c}\text { Total } \\
\text { Coligações }\end{array}$} & \multirow{2}{*}{$\begin{array}{c}\text { Total } \\
\text { Candidaturas } \\
\text { Isoladas }\end{array}$} & \multirow{2}{*}{$\begin{array}{l}\text { Total Geral } \\
\text { Candidaturas }\end{array}$} \\
\hline & & FORTE & MÉDIO & FRACO & & & \\
\hline \multirow{7}{*}{$\begin{array}{c}\text { Deputado } \\
\text { Federal }\end{array}$} & 1986 & 1 & - & - & 1 & 6 & 7 \\
\hline & 1990 & 3 & - & - & 3 & 3 & 6 \\
\hline & 1994 & 1 & 1 & 1 & 3 & 3 & 6 \\
\hline & 1998 & 4 & - & - & 4 & 7 & 11 \\
\hline & 2002 & 4 & - & 3 & 7 & 3 & 10 \\
\hline & Tot. (N) & $13^{*}$ & 1 & 4 & 18 & 22 & 40 \\
\hline & Tot. (\%) & 32,5 & 2,5 & 10,0 & 45,0 & 55,0 & 100,0 \\
\hline \multirow{7}{*}{$\begin{array}{l}\text { Deputado } \\
\text { Estadual }\end{array}$} & 1986 & 1 & - & - & 1 & 7 & 8 \\
\hline & 1990 & 3 & - & - & 3 & 3 & 6 \\
\hline & 1994 & 1 & 1 & 1 & 3 & 1 & 4 \\
\hline & 1998 & 3 & - & - & 3 & 6 & 9 \\
\hline & 2002 & 3 & - & 3 & 6 & 6 & 12 \\
\hline & Tot. (N) & $11^{*}$ & 1 & 4 & 16 & 23 & 39 \\
\hline & Tot. (\%) & 28,0 & 3,0 & 10,0 & 41,0 & 59,0 & 100,0 \\
\hline
\end{tabular}

Fonte: TRE/SC.

* Na realidade, entre as coligações consideradas acima como tendo grau forte de coerência ideológica, duas (uma para deputado federal e uma para deputado estadual) envolviam apenas pequenos partidos não classificados ideologicamente, por falta de informações. Para os objetivos desta pesquisa, o mais importante é o fato de não representarem um tipo de coligação claramente inconsistente (que poderia ser punida pelo eleitor), já que envolve partidos com baixíssima representatividade e sem perfil ideológico nítido.

Como é possível ver, nas eleições proporcionais para deputado estadual e federal apenas cerca de $10 \%$ das candidaturas foram de coligações inconsistentes, cerca de $87 \%$ das candidaturas foram de partidos isolados ou coligações envolvendo apenas partidos do mesmo "campo" e cerca de 3\% envolveram coligações "semi-consistentes" (ver nota ao pé da Tabela 3).

Mas, deve-se notar que na última eleição (2002), as coligações inconsistentes representaram $25 \%$ das candidaturas na eleição para deputado estadual (3 das 12 candidaturas) e 30\% na eleição para deputado federal (3 das 10 candidaturas), o que indica um forte crescimento deste tipo de coligação em relação a todo período anterior, já que apenas duas entre as 57 candidaturas (3,5\% do total) lançadas no período 1986.98 para as eleições a deputado estadual e deputado federal eram inconsistentes. 
Como se trata de uma única eleição, não é possível concluir, a partir destes dados, que se trata de uma tendência. Porém, dado que para os demais cargos ocorreu o mesmo fenômeno, e levando-se em consideração, especialmente, a mudança na política de alianças do PT, é possível supor que se trata mesmo de uma tendência geral de ampliação do leque ideológico de coligações.

\section{Análise dos padrões de coligação por partidos selecionados}

Uma análise mais detalhada do comportamento dos principais partidos nos fornece outras informações relevantes sobre o tema das coligações nas eleições para prefeito. Algumas das principais conclusões sobre esse aspecto são apresentadas, a seguir, a partir dos dados da Tabela 4 e dos Anexos 1 e 2.

\section{Tabela 4}

Grau de coerência ideológica das coligações, para os seis maiores partidos

(Prefeito - Santa Catarina 1988-2004)

\begin{tabular}{|c|c|c|c|c|c|c|c|c|}
\hline \multirow{2}{*}{ Partido } & \multirow{2}{*}{ Ano } & \multicolumn{3}{|c|}{ Grau de Coerência Ideológica } & \multirow{2}{*}{$\begin{array}{c}\text { Total } \\
\text { Coligações } \\
\text { (\%) }\end{array}$} & \multirow{2}{*}{$\begin{array}{l}\text { Total Cand. } \\
\text { Isoladas } \\
(\%)\end{array}$} & \multirow{2}{*}{$\begin{array}{c}\text { Total } \\
\text { Geral } \\
\text { Cand. (N) }\end{array}$} & \multirow{2}{*}{$\begin{array}{c}\mathbf{N}^{\circ} \\
\text { Municípios }\end{array}$} \\
\hline & & $\begin{array}{l}\text { FORTE } \\
(\%)\end{array}$ & $\begin{array}{c}\text { MÉDIO } \\
(\%)\end{array}$ & $\begin{array}{c}\text { FRACO } \\
(\%)\end{array}$ & & & & \\
\hline \multirow{6}{*}{$\begin{array}{l}\text { PP } \\
\text { (PPB/ } \\
\text { PPR/PDS) }\end{array}$} & 1988 & 53,0 & 4,0 & 11,0 & 68,0 & 32,0 & 182 & 199 \\
\hline & 1992 & 54,0 & 14,0 & 16,0 & 84,0 & 16,0 & 238 & 260 \\
\hline & 1996 & 29,0 & 23,0 & 29,0 & 82,0 & 18,0 & 272 & 293 \\
\hline & 2000 & 32,0 & 33,0 & 24,0 & 89,0 & 11,0 & 281 & 293 \\
\hline & 2004 & 20,0 & 31,0 & 43,0 & 94,0 & 6,0 & 284 & 293 \\
\hline & MÉDIA & 36,0 & 23,0 & 26,0 & 85,0 & 15,0 & 1257 & \\
\hline \multirow{6}{*}{ PFL } & 1988 & 58,0 & 11,0 & 11,0 & 80,0 & 20,0 & 170 & 199 \\
\hline & 1992 & 54,0 & 16,0 & 19,0 & 89,0 & 11,0 & 226 & 260 \\
\hline & 1996 & 33,0 & 30,0 & 28,0 & 91,0 & 9,0 & 252 & 293 \\
\hline & 2000 & 35,0 & 34,0 & 24,0 & 93,0 & 7,0 & 278 & 293 \\
\hline & 2004 & 20,0 & 34,0 & 41,0 & 94,0 & 6,0 & 270 & 293 \\
\hline & MÉDIA & 38,0 & 26,0 & 26,0 & 90,0 & 10,0 & 1196 & \\
\hline
\end{tabular}


OPINIÃO PÚBLICA, Campinas, vol. 12, no 1, Abril/Maio, 2006, p. 136-163

Tabela 4 (continuação)

\begin{tabular}{|c|c|c|c|c|c|c|c|c|}
\hline \multirow{2}{*}{ Partido } & \multirow{2}{*}{ Ano } & \multicolumn{3}{|c|}{ Grau de Coerência Ideológica } & \multirow{2}{*}{$\begin{array}{c}\text { Total } \\
\text { Coligações } \\
\text { (\%) }\end{array}$} & \multirow{2}{*}{$\begin{array}{l}\text { Total Cand. } \\
\text { Isoladas } \\
\text { (\%) }\end{array}$} & \multirow{2}{*}{$\begin{array}{c}\text { Total } \\
\text { Geral } \\
\text { Cand. (N) }\end{array}$} & \multirow{2}{*}{$\begin{array}{c}\mathbf{N}^{\circ} \\
\text { Municípios }\end{array}$} \\
\hline & & $\begin{array}{c}\text { FORTE } \\
\text { (\%) }\end{array}$ & $\begin{array}{c}\text { MÉDIO } \\
\text { (\%) }\end{array}$ & $\begin{array}{c}\text { FRACO } \\
\text { (\%) }\end{array}$ & & & & \\
\hline \multirow{6}{*}{ PMDB } & 1988 & 1,0 & 24,0 & 1,0 & 25,0 & 75,0 & 195 & 199 \\
\hline & 1992 & 4,0 & 55,0 & 10,0 & 69,0 & 31,0 & 238 & 260 \\
\hline & 1996 & 9,0 & 51,0 & 12,0 & 72,0 & 28,0 & 288 & 293 \\
\hline & 2000 & 7,0 & 51,0 & 15,0 & 74,0 & 26,0 & 283 & 293 \\
\hline & 2004 & 6,0 & 50,0 & 26,0 & 82,0 & 18,0 & 292 & 293 \\
\hline & MÉDIA & 6,0 & 47,0 & 14,0 & 67,0 & 33,0 & 1296 & \\
\hline \multirow{6}{*}{ PSDB } & 1988 & - & 55,0 & - & 55,0 & 45,0 & 11 & 199 \\
\hline & 1992 & 8,0 & 72,0 & 13,0 & 93,0 & 7,0 & 100 & 260 \\
\hline & 1996 & 16,0 & 59,0 & 19,0 & 93,0 & 7,0 & 162 & 293 \\
\hline & 2000 & 11,0 & 61,0 & 11,0 & 93,0 & 7,0 & 192 & 293 \\
\hline & 2004 & 7,0 & 51,0 & 36,0 & 94,0 & 6,0 & 254 & 293 \\
\hline & MÉDIA & 10,0 & 58,0 & 24,0 & 93,0 & 7,0 & 719 & \\
\hline \multirow{6}{*}{ PDT } & 1988 & 1,0 & 17,0 & 33,0 & 51,0 & 48,0 & 70 & 199 \\
\hline & 1992 & 10,0 & 38,0 & 37,0 & 84,0 & 16,0 & 164 & 260 \\
\hline & 1996 & 5,0 & 28,0 & 61,0 & 94,0 & 6,0 & 183 & 293 \\
\hline & 2000 & 10,0 & 25,0 & 58,0 & 92,0 & 8,0 & 158 & 293 \\
\hline & 2004 & 4,0 & 12,0 & 82,0 & 98,0 & 2,0 & 117 & 293 \\
\hline & MÉDIA & 6,0 & 26,0 & 55,0 & 87,0 & 13,0 & 692 & \\
\hline \multirow{6}{*}{ PT } & 1988 & 2,0 & 1,0 & - & 4,0 & 96,0 & 84 & 199 \\
\hline & 1992 & 15,0 & 49,0 & 4,0 & 67,0 & 33,0 & 115 & 260 \\
\hline & 1996 & 11,0 & 41,0 & 5,0 & 57,0 & 43,0 & 120 & 293 \\
\hline & 2000 & 17,0 & 25,0 & 8,0 & 50,0 & 50,0 & 161 & 293 \\
\hline & 2004 & 9,0 & 28,0 & 31,0 & 68,0 & 32,0 & 242 & 293 \\
\hline & MÉDIA & 11,0 & 30,0 & 13,0 & 54,0 & 46,0 & 722 & \\
\hline
\end{tabular}

Fonte: TRE- SC.

Obs.: As porcentagens foram "arredondadas". 
Sobre o Partido Progressista (PP/PPB/PDS/PPR)

Em relação às eleições para o governo estadual, entre 1986 e 2002, por duas vezes o PP lançou candidatos isoladamente; em duas eleições só fez coligações à direita, e em 1998 fez uma grande coligação que envolvia, além de outros partidos de direita, o PSDB (de centro). Em todas as eleições proporcionais, o PP lançou candidaturas isoladamente ou em coligação apenas com partidos à direita. No que se refere às eleições para prefeito, na média do período a maior proporção de candidaturas é de coligações consistentes (36\%). Se somarmos a estes os casos de candidaturas isoladas, teremos cerca de $51 \%$ do conjunto das candidaturas, contra $26 \%$ de coligações mais inconsistentes (além de outros $23 \%$ de coligações envolvendo partidos de centro). Isto indica um grau razoável de consistência ideológica. De qualquer forma, a tendência mais geral ao longo do período foi de crescimento contínuo das coligações inconsistentes e declínio das consistentes. Em 2004, somando-se as coligações com grau "médio" e "fraco" de coerência ideológica, temos 74\% das candidaturas, contra 15\% em 1988.

Sobre o Partido da Frente Liberal (PFL)

As tendências gerais são muito semelhantes às do PP. Assim, das cinco eleições que disputou para governador, o partido fez coligações à direita por duas vezes e saiu isolado em outras duas, tendo participado em 1998 daquela mesma coligação que envolvia PPB e PSDB. Nas eleições proporcionais, o PFL teve o mesmo comportamento do PP: ou lançou candidaturas isoladamente, ou em coligação apenas com partidos à direita. Para prefeito, o perfil médio e a trajetória ao longo do tempo são também muito semelhantes às do PP.

\section{Sobre o Partido do Movimento Democrático Brasileiro (PMDB)}

Em 3 das 5 eleições para governador, o partido lançou candidato isoladamente; em uma outra, coligou-se apenas com o PSDB, também de centro. Apenas na eleição de 1994 lançou candidato apoiado por pequenos partidos de esquerda e direita, simultaneamente. Nas eleições proporcionais, lançou candidaturas próprias em 4 das 5 eleições; em 1994, porém, participou de uma coligação ideologica-mente inconsistente, igual à realizada para o governo de estado. Quanto às eleições para prefeito, com a exceção do PT, o PMDB foi, entre os grandes partidos, o que lançou a maior proporção de candidaturas isoladas (33\% do total de candidaturas no período). Quanto ao tipo de coligações que realizou, há oscilações: em 1988, 1996 e 2000, coligou-se um pouco mais com a direita, em 1992 e 2004, um pouco mais com a esquerda. 
Sobre o Partido da Social Democracia Brasileira (PSDB)

No que se refere ao governo do estado, este foi o partido que mais oscilou: lançou candidatura isolada em 1990; coligou-se com uma frente de partidos de esquerda em 1994; com um conjunto de partidos de direita em 1998 (em apoio a Espiridião Amin, do PP) e com o PMDB (centro) em 2002. Das 4 eleições proporcionais de que participou, em 3 lançou candidaturas isoladamente; em 1994 participou da Frente Popular, uma coligação que envolvia seis partidos de esquerda. Nas eleições para prefeito, a tendência mais geral foi um deslocamento para a direita após 1994: entre 1988 e 1992 as coligações eram preferencialmente com partidos situados à esquerda; entre 1996 e 2004, a preferência foi coligar com partidos à direita18.

\section{Sobre o Partido Democrático Trabalhista (PDT)}

Nas eleições para governador, o partido tem se mantido "coerente": lançou candidatura isolada em 1986; participou de coligações à esquerda em 1990, 1994 e 1998 (Frentes Populares); em 2002 não participou formalmente de nenhuma candidatura, mas apoiou informalmente o candidato do PPS no $1^{\circ}$ turno e o do PMDB no $2^{\circ}$ turno, contra o candidato do PPB. Nas eleições proporcionais, lançou candidaturas isoladas em 1986; em 1990, 1994 e 1998, participou da Frente Popular (frente de esquerda que em 1994 incluiu o PSDB) e em 2002 coligou-se com o PTB.

Com relação às eleições para prefeito, o PDT é o mais eclético dentre os maiores partidos na realização de coligações. Coliga-se com partidos de todos os pontos do espectro partidário, sendo que suas proporções de coligações inconsistentes são maiores do que as dos demais partidos, em cada uma das cinco eleições; $55 \%$ das candidaturas de que participou em todo o período tiveram este

\footnotetext{
18 Em Santa Catarina esta mudança é acentuada: em 1994, a seção estadual do PSDB foi uma das únicas a se posicionar contra a coligação PSDB.PFL em apoio a Fernando Henrique Cardoso, tendo formado, nas eleições para governador, uma coligação com os partidos de esquerda. Com a eleição do presidente Fernando H. Cardoso, o grupo mais à esquerda do partido ficou marginalizado e algumas de suas lideranças mais expressivas (como Jaison Barreto e Dirceu Carneiro) saíram do partido (e da política). Estas saídas, aliadas às vantagens associadas à ocupação da presidência da República, favorecem o predomínio dos grupos mais pragmáticos no interior do partido. Considerando apenas as coligações com grau médio de consistência ideológica, em 1992, para cada coligação com um partido à direita, o PSDB fazia três com partidos à esquerda. Já em 1996 a situação se inverteu: as coligações com partidos à direita superam em cerca de $75 \%$ as com partidos à esquerda. Nas eleições de 2000, o número de coligações (com "grau de consistência média") com partidos à direita foi 5 vezes maior do que à esquerda; em 2004, esta relação cai um pouco (para quase 4 vezes). Essa mudança é emblemática nas eleições para prefeito de Florianópolis em 1996 e 2000 e para governador em 1998, em que o partido irá se coligar com o PPB e, após a vitória nestas eleições, irá participar dos governos de Ângela e Esperidião Amin.
} 
padrão. Além disso, estas coligações inconsistentes cresceram muito, passando de $33 \%$ das candidaturas de que o partido participou em 1988, para 82\% em 2004.

Sobre o Partido dos Trabalhadores (PT)

Nas eleições para o governo estadual, o PT lançou candidatura isolada em 1986; em 1990, 1994 e 1998, participou de coligações exclusivamente com partidos de esquerda. Em 2002, acompanhando a estratégia nacional do partido, além de se coligar com outros partidos de esquerda, envolveu também o PL na coligação. Nas eleições proporcionais, teve trajetória semelhante à do PDT, com exceção de 2002, quando se coligou com o PCdoB e com o PL.

Quanto às eleições para prefeito, o PT foi o partido que mais lançou candidatos isoladamente: $46 \%$ das 722 candidaturas de que participou em todo o período. Na primeira eleição analisada - 1988 - a estratégia do partido foi lançar candidaturas isoladas ( $96 \%$ do total das candidaturas). A partir de 1992, porém, houve uma inversão, de cada 3 candidaturas, 2 foram em coligações. Embora tenha havido uma redução do percentual de coligações em 1996 e 2000, em 2004 este percentual voltou a crescer e alcançou seu ponto máximo do período: $68 \%$. No que diz respeito ao padrão das candidaturas, o PT é o partido com maior consistência ideológica: as coligações inconsistentes representam $13 \%$ do total de candidaturas; em contraste com este número, temos $57 \%$ das candidaturas lançadas de forma isolada ou em coligação apenas com partidos de esquerda. Nas coligações, a tendência predominante ocorre com partidos de centro, com 30\% das candidaturas. Estas cresceram enormemente entre 1988 e 1992 (de 1\% para 49\% do total das candidaturas lançadas), diminuindo em seguida (em 2000 representaram 25\% das candidaturas de que o PT participou e em 2004, 28\%). As coligações envolvendo partidos de esquerda cresceram até 2000, declinando em 2004. As eleições de 2002 parecem ter representado realmente um ponto de inflexão na história do partido, na medida em que as coligações mais inconsistentes ideologicamente deram um salto entre as eleições municipais imediatamente anteriores e posteriores àquela eleição: de $8 \%$ do total das candidaturas em 2000, passaram a 31\% em 2004.

\section{A "resposta" dos eleitores aos diferentes tipos de candidaturas}

Esta seção analisa os resultados das diferentes estratégias eleitorais partidárias, visando testar preliminarmente a hipótese de que os eleitores puniriam coligações ideologicamente inconsistentes. Esta hipótese deriva da hipótese inicial deste estudo, de que o posicionamento ideológico do partido - seja pelo seu programa, pelas declarações de seus líderes, ou pelo comportamento dos detentores de 
mandatos públicos - repercutiria na opinião pública e formaria uma imagem partidária junto ao eleitorado. Essa imagem partidária, por sua vez, poderia atuar como uma limitação ao padrão ideológico de coligação "permitido" ao partido, na medida em que realizar coligações fora de um padrão minimamente esperado poderia ter custos político-eleitorais futuros. Se a hipótese estiver correta, isso resultaria em taxas de eleição menores para os candidatos apoiados por coligações ideologicamente inconsistentes, devido à punição por parte dos eleitores frente àqueles lançados em candidaturas isoladas ou por coligações ideologicamente consistentes.

Este teste preliminar analisa apenas as eleições para os cargos majoritários (governador e prefeito), e não utiliza variáveis de controle.

Nas eleições para governador, o número é muito pequeno para estabelecer padrões estatísticos minimamente robustos. De toda forma, os dados são os seguintes: das 15 candidaturas isoladas lançadas nas cinco eleições, entre 1986 e 2002, apenas uma foi vitoriosa (o que significa $7 \%$ sobre o total deste tipo de candidatura). De outro lado, das 11 candidaturas que envolviam coligações, $36 \%$ delas (ou seja, 4) foram vencedoras, o que atesta o maior rendimento da estratégia coligacionista. Dentre as coligações, temos os seguintes percentuais de vitoriosas: 33\% (2 das 6) das coligações mais consistentes ideologicamente; $50 \%$ (1 das 2) das coligações semi-consistentes e 33\% (1 das 3) das coligações inconsistentes.

Quanto às eleições para prefeito, a Tabela 5 mostra as proporções de candidaturas vencedoras sobre o total de candidaturas de cada tipo.

Tabela 5

Proporção de candidaturas vencedoras, segundo o tipo de candidaturas, nas eleições para prefeito (Santa Catarina 1988-2004)

\begin{tabular}{|c|c|c|c|c|c|c|}
\hline \multirow{2}{*}{ Ano } & \multicolumn{3}{|c|}{ Grau de Coerência Ideológica } & \multirow{2}{*}{$\begin{array}{c}\text { Total } \\
\text { Coligações } \\
\text { (\%) }\end{array}$} & \multirow{2}{*}{$\begin{array}{c}\text { Total } \\
\text { Candidaturas } \\
\text { Isoladas (\%) }\end{array}$} & \multirow{2}{*}{$\begin{array}{c}\text { Total } \\
\text { Candidaturas } \\
\text { (\%) }\end{array}$} \\
\hline & FORTE (\%) & MÉDIO (\%) & FRACO (\%) & & & \\
\hline 1988 & 44,0 & 37,0 & 46,0 & 43,0 & 31,0 & 35,0 \\
\hline 1992 & 39,0 & 51,0 & 50,0 & 46,0 & 33,0 & 41,0 \\
\hline 1996 & 42,0 & 50,0 & 64,0 & 51,0 & 24,0 & 42,0 \\
\hline 2000 & 38,0 & 51,0 & 42,0 & 45,0 & 29,0 & 39,0 \\
\hline 2004 & 39,0 & 48,0 & 47,0 & 46,0 & 20,0 & 39,0 \\
\hline Tot. Vit. (\%) & 40,0 & 50,0 & 51,0 & 47,0 & 28,0 & 39,0 \\
\hline Tot. Vit. (N) & 263 & 431 & 275 & 969 & 369 & 1338 \\
\hline Tot. Cand. & 662 & 866 & 541 & 2069 & 1321 & 3390 \\
\hline
\end{tabular}

Fonte: TRE/SC.

Obs.: Percentuais não somam $100 \%$ nem nas linhas, nem nas colunas. Eles representam a divisão do número de candidaturas vencedoras, pelo número total de candidaturas (para cada tipo). 
No conjunto do período, vemos que das 2.069 candidaturas lançadas por coligações, $47 \%$ delas foram vencedoras, enquanto das 1.321 candidaturas isoladas, apenas $28 \%$ foram vitoriosas. Isso sugere, como no caso das eleições para governador, um rendimento bem superior da estratégia de se coligar, frente à estratégia de concorrer isoladamente. Entre as coligações, as que tiveram maior rendimento foram aquelas com grau fraco de coerência ideológica ( $51 \%$ delas foram vitoriosas) e médio (50\%), enquanto as coligações com forte coerência ideológica tiveram um rendimento menor ( $40 \%$ delas alcançaram a vitória). Com pequenas variações, estas tendências são válidas para cada uma das eleições individualmente ${ }^{19}$.

Assim como para as eleições para governador, a hipótese mencionada anteriormente não foi também corroborada pelos dados referentes às eleições para prefeito; não houve punição dos eleitores às coligações ideologicamente inconsistentes. Pelo contrário, a estratégia com maior rendimento nas eleições para prefeito, em Santa Catarina, entre 1988 e 2004, foi lançar candidaturas em coligações que envolvessem partidos de pelo menos dois campos ideológicos diferentes, incluindo aí as que envolviam partidos situados em campos opostos (direita e esquerda).

As conclusões acima devem ser vistas com ressalvas, na medida em que não foram introduzidas variáveis de controle na análise. Dessa forma, não é possível afirmar categoricamente que o tipo de coligação teve um efeito independente sobre a probabilidade de sucesso da candidatura, ou se alguma outra variável poderia ter influência sobre os resultados encontrados. Além disso, foram analisadas aqui apenas as eleições majoritárias. De toda forma, cremos que a análise acima possa servir como um indício - a ser verificado de forma mais robusta por análises mais sofisticadas - de que coligações inconsistentes não são punidas pelos eleitores.

19 A única diferença digna de nota é nas eleições de 1988, em que a proporção de candidaturas vitoriosas por coligações de grau de coerência ideológica forte era quase igual à proporção de candidaturas vitoriosas por coligações de grau de coerência ideológica fraco. 


\section{Considerações finais}

A análise aqui realizada não contempla as eleições para o cargo de vereador. Além disso, é necessário analisar o impacto de outros fatores relativos à estrutura de oportunidades em que se processam as eleições, por exemplo, o tamanho e o número de partidos, para que se possa ter uma compreensão mais abrangente do fenômeno das coligações em Santa Catarina. De qualquer forma, é justamente frente à insuficiência de análises empíricas que o trabalho pode contribuir para o conhecimento de certos aspectos relativos às estratégias partidárias de coligação. Destacamos as seguintes conclusões:

$1^{a}$ ) É possível dizer que havia um razoável grau de consistência ideológica das coligações, nas eleições para governador, deputado federal, deputado estadual (e em menor grau para prefeito), em Santa Catarina, no início do período. Mesmo no conjunto do período, os percentuais de coligações ideologicamente inconsistentes foram: $11,5 \%$ das candidaturas a governador (ou seja, uma em cada nove); $10 \%$ das candidaturas para deputado federal e estadual (uma em cada dez, portanto) e $16 \%$ das candidaturas para prefeito (uma em cada seis). Note-se que se considerarmos que o peso das questões ideológicas na política local é menor, ampliando-se a possibilidade de realização de coligações inconsistentes, esta relativa consistência no nível municipal torna-se ainda mais significativa. Esta conclusão contrasta com as análises recorrentes, especialmente nos meios de comunicação, que apontavam o sistema partidário brasileiro como totalmente caótico desde o final da década de 1980; na realidade os dados relativos até o final da década de 1990 estão em consonância com análises como as de Kinzo (1990) e Figueiredo e Limongi (1999), que pleiteiam certo grau de diferenciação ideológica entre os partidos;

$2^{a}$ ) Os dados analisados não revelam um comportamento homogêneo de todos os partidos em relação ao grau de consistência ideológica das coligações de que participam. Assim, só para dar um exemplo, o PT, no conjunto do período, coligouse, nas eleições para governador e nas eleições proporcionais, apenas uma vez com um partido de direita (o PL, em 2002) e apresentou apenas $13 \%$ de coligações "inconsistentes", num total de 722 candidaturas a prefeito de que participou. 0 PDT, por outro lado, embora não tenha se coligado com nenhum partido de centro ou de direita nas eleições para governador, e apenas uma vez (em 2002) com o PTB nas eleições proporcionais, das candidaturas de que participou para prefeito, entre 1988 e 2004, 55\% envolviam partidos de direita e outras 26\% envolviam partidos de centro; 
$3^{a}$ ) As coligações realizadas nas eleições de âmbito estadual (governador, deputado federal e estadual) mostraram maior consistência ideológica do que as coligações realizadas nas eleições para prefeito. Paralelamente, nas eleições proporcionais (e, de certa forma, nas eleições para governador), as coligações inconsistentes foram as que tiveram menor rendimento eleitoral (embora tenham tido maior rendimento do que a estratégia de lançar candidatos isoladamente). Estes dados podem ser um indício de que em âmbito estadual - comparativamente ao âmbito municipal - os eleitores prestam mais atenção na consistência ideológica das coligações e os partidos levam um pouco mais em consideração os limites ideológicos, ao definirem suas estratégias coligacionistas;

$4^{\text {a) }}$ Uma tendência se mostra persistente no período: a de aumento de coligações, especialmente as de grau de coerência ideológica médio e fraco. Diversos processos podem ter contribuído para esta tendência:

1. No início do período, lançar candidaturas isoladamente foi a estratégia preferencial de vários partidos, visando consolidar suas bases organizacionais e testar sua força eleitoral. O patamar inicial de coligações, portanto, é baixo;

2. O aumento da fragmentação do sistema partidário - em âmbito estadual e municipal - incentivou o aumento do número de coligações (incluindo as menos consistentes ideologicamente), como estratégia para atenuar o impacto dessa fragmentação sobre a competição eleitoral;

3. A diluição gradual da clivagem entre os partidos (e políticos) que apoiaram e os que se opuseram ao regime autoritário pós-64 facilitou coligações entre partidos de campos ideológicos diferente;

4. O fim da Guerra Fria atenuou os obstáculos ideológicos para a efetivação de coligações inconsistentes;

5. A mudança de posicionamento ideológico do PT em direção ao centro (que se torna mais clara a partir de 2002), alarga ainda mais o campo de possibilidades de realização de coligações ${ }^{20}$;

6. As coligações - de qualquer tipo - têm um rendimento superior às candidaturas isoladas; para o caso das eleições a prefeito (embora não para as eleições

\footnotetext{
20 A inflexão do PT em direção a posições mais moderadas segue uma trajetória nada incomum em partidos socialistas e social-democratas em âmbito internacional. Após as derrotas de 1989 e 1994 (e, depois, 1998), o PT - ou, pelo menos suas correntes dominantes - e Lula avaliaram que para vencer a eleição presidencial seria necessário um abrandamento das posições mais radicais, de forma a abranger um maior número de aliados entre os setores organizados da sociedade e atrair parcelas maiores do eleitorado. Aceitando a tese de Panebianco (1988) - de que partidos precisam distribuir incentivos coletivos, relacionados à "identidade" e à "ideologia" do partido, para que seus "membros" (simpatizantes, filiados, militantes, dirigentes) participem politicamente -, a reorientação do PT representou uma decisão, por parte das facções majoritárias do partido, de correr o risco de perder "membros", para ganhar mais eleitores.
} 
proporcionais), a estratégia de lançar coligações com graus fraco ou médio de coerência ideológica, não apenas não é punida pelos eleitores, como tem um rendimento superior ao das coligações ideologicamente mais consistentes. A percepção desta tendência por parte dos partidos pode ter contribuído nas decisões que levaram a uma estratégia crescente de aumento das coligações, incluindo as mais inconsistentes ideologicamente.

Vários destes processos descritos acima devem ter pesado no aumento das coligações de grau médio de coerência ideológica. Quanto ao aumento das coligações mais inconsistentes, a inflexão política do PT parece ter sido um peso determinante, como mostra a Tabela 6.

Tabela 6

Coligações ideologicamente inconsistentes (direita-esquerda) (\%)

\begin{tabular}{|c|c|c|c|c|c|}
\hline Período & N $^{\circ}$ Eleições & Governador & Deputado Federal & Deputado Estadual & Prefeito \\
\hline $1986 / 2000$ & $(4)^{*}$ & 5,0 & 3,0 & 4,0 & 12,0 \\
\hline $2002 / 2004$ & $(1)^{* *}$ & 40,0 & 30,0 & 25,0 & 29,0 \\
\hline
\end{tabular}

Fonte: TRE/SC.

* Governador, deputado federal e estadual = 1986, 1990, 1994 e 1998; prefeito = 1988, 1992, 1996 e 2000.

$* *$ Governador, deputado federal e estadual $=2002$; prefeito $=2004$.

Esta Tabela resume as proporções de coligações ideologicamente mais inconsistentes (apresentadas nas Tabelas 1 a 3), contrastando, para cada cargo, as quatro primeiras eleições (período 1986-2000) com a última (período 2002-2004).

Seus dados mostram que nas quatro primeiras eleições para governador, a média de coligações que envolviam simultaneamente partidos de esquerda e de direita foi de apenas 5\%; na eleição de 2002, este percentual sobe para $40 \%$. 0 mesmo crescimento brutal ocorre nas eleições proporcionais e nas eleições para prefeito. Como todos os demais processos apontados acima operaram gradualmente ao longo do período estudado, a explicação que parece mais plausível para este enorme salto de coligações ideologicamente inconsistentes é a da inflexão política do PT, que fica muito clara a partir de 2002. Concordando com a avaliação de Singer (2000), de que o PT constituía, pelo menos até recentemente, a "espinha dorsal", em termos ideológicos do sistema partidário, aquela inflexão 
parece ter sido, dos processos mencionados mais acima, o que teve maior influência na perda de nitidez ideológica no conjunto do sistema partidário, resultando no vertiginoso aumento das coligações inconsistentes.

Evidentemente os dados aqui apresentados permitem fazer afirmações sobre o sistema partidário brasileiro como um todo. Mas, os dados parecem refletir uma perda de nitidez ideológica que ocorre em âmbito nacional e, assim, pode-se tentar alguma reflexão sobre as tendências futuras: embora seja difícil, neste momento, prever os desdobramentos da crise por que passa o PT, parece difícil que o partido volte a se configurar como "a espinha dorsal" do sistema partidário, em termos ideológicos. Talvez o próprio continuum esquerda-direita como referencial para a análise possa perder parte de seu poder preditivo do comportamento dos partidos e seus membros; é possível também que este continuum ainda mantenha sua utilidade, mas a classificação dos partidos que tem predominado até agora talvez tenha que ser repensada, especialmente com o eventual crescimento de partidos como o P.SOL e o PSTU. 
OPINIÃO PÚBLICA, Campinas, vol. 12, no 1, Abril/Maio, 2006, p. 136-163

Anexo 1

Candidaturas às eleições para governador (Santa Catarina 1986-2002)

\begin{tabular}{|c|c|c|c|c|}
\hline Ano & Candidatos & $\begin{array}{l}\text { Cand. } \\
\text { Isoladas }\end{array}$ & Coligações & $\begin{array}{l}\text { Total } \\
\text { Cand. }\end{array}$ \\
\hline \multirow{6}{*}{1986} & AMILCAR GAZANIGA & PDS & & \\
\hline & PEDRO IVO & PMDB & & \\
\hline & RAUL GÜINTHER & PT & & \\
\hline & MANOEL DIAS & PDT & & \\
\hline & VILSON KLEINUBING & & PFL/PTB/PDC & \\
\hline & TOTAL & 4 & 1 & 5 \\
\hline \multirow{7}{*}{1990} & PAULO AFONSO & PMDB & & \\
\hline & DIRCEU CARNEIRO & PSDB & & \\
\hline & AMÉRICO FARIA & PRN & & \\
\hline & NILTON MATHEUS & PMN & & \\
\hline & VILSON KLEINUBING & & PDS/PFL/PTB/PDC/PL/PSC & \\
\hline & NELSON WEDEKIN & & PDT/PT/PCB/PCdoB & \\
\hline & TOTAL & 4 & 2 & 6 \\
\hline \multirow{5}{*}{1994} & ÂAGELA AMIN & PPR & & \\
\hline & JORGE BORNHAUSEN & PFL & & \\
\hline & PAULO AFONSO & & PMDB/PSD/PTRB/PRP/PMN/PV & \\
\hline & NELSON WEDEKIN & & PDT/PT/PPS/PCdoB/PSDB/PSB & \\
\hline & TOTAL & 2 & 2 & 4 \\
\hline \multirow{7}{*}{1998} & ESPERIDIAO AMIN & & $\begin{array}{c}\mathrm{PPB} / \mathrm{PFL} / \mathrm{PTB} / \mathrm{PSDB} / \\
\mathrm{PSL} / \mathrm{PST} / \mathrm{PL} / \mathrm{PRTB} / \mathrm{PGT} / \\
\text { PRN/PTdoB/PSDC }\end{array}$ & \\
\hline & PAULO AFONSO & PMDB & & \\
\hline & MILTON MENDES & & $\begin{array}{c}\mathrm{PT} / \mathrm{PDT} / \mathrm{PCdoB} / \mathrm{PPS} / \mathrm{PSB} / \\
\mathrm{PCB} / \mathrm{PMN} / \mathrm{PSN}\end{array}$ & \\
\hline & JOANINHA DE OLIVEIRA & PSTU & & \\
\hline & ROGERIO PORTANOVA & PV & & \\
\hline & CARLOS A. MACHADO & PSC & & \\
\hline & TOTAL & 4 & 2 & 6 \\
\hline \multirow{7}{*}{2002} & ANTONIO BELLO JUNIOR & & PSB/PSD & \\
\hline & ESPERIDIAO AMIN & & PPB/PFL/PSL/PRTB/PST/PTdoB & \\
\hline & GILMAR SALGADO & PSTU & & \\
\hline & JOSÉ FRITSCH & & PT/PL/PCdoB/PMN & \\
\hline & LUIZ HENRIQUE SILVEIRA & & PMDB/PSDB & \\
\hline & SÉRGIO GRANDO & & PPS/PV/PSDC & \\
\hline & TOTAL & 1 & 5 & 6 \\
\hline
\end{tabular}

Fonte: TRE - SC. 


\section{Anexo 2}

Coligações partidárias nas eleições proporcionais

(Deputados federais e estaduais - Santa Catarina 1986-2002)

\begin{tabular}{|c|c|c|c|}
\hline Ano & Cargo & Coligações & $\begin{array}{l}\text { Cand. } \\
\text { Isoladas }\end{array}$ \\
\hline \multirow{7}{*}{1986} & \multirow{6}{*}{$\begin{array}{c}\text { Dep. Federal } \\
\text { e } \\
\text { Dep. Estadual }\end{array}$} & PTB-PDC-PFL & PMDB \\
\hline & & & PT \\
\hline & & & PDT \\
\hline & & & PDS \\
\hline & & & PCdoB \\
\hline & & & PCB \\
\hline & Dep. Estadual & & $\mathrm{PH}$ \\
\hline \multirow{3}{*}{1990} & \multirow{3}{*}{$\begin{array}{c}\text { Dep. Federal } \\
\text { e } \\
\text { Dep. Estadual }\end{array}$} & PDS-PFL-PTB-PDC-PL-PSC & PMDB \\
\hline & & PT-PDT-PCB-PCdoB & PSDB \\
\hline & & PRN-PTR & PMN \\
\hline \multirow{5}{*}{1994} & \multirow{3}{*}{$\begin{array}{c}\text { Dep. Federal } \\
\text { e } \\
\text { Dep. Estadual }\end{array}$} & PT-PDT-PPS-PSB-PCdoB-PCB-PSDB & PSTU \\
\hline & & PPR-PFL-PTB-PL-PSC & \\
\hline & & PMDB-PV-PMN-PSD-PRP-PTRB & \\
\hline & \multirow{2}{*}{ Dep. Federal } & & PRONA \\
\hline & & & PRN \\
\hline \multirow{8}{*}{1998} & \multirow{5}{*}{$\begin{array}{c}\text { Dep. Federal } \\
\text { e } \\
\text { Dep. Estadual }\end{array}$} & PT-PDT-PPS-PCdoB-PCB-PSB-PMN-PSN & PMDB \\
\hline & & PL-PTB-PRN-PAN-PST-PRTB & PSDB \\
\hline & & & PV \\
\hline & & & PSTU \\
\hline & & & PSC \\
\hline & \multirow{2}{*}{ Dep. Federal } & PPB-PFL & PRONA \\
\hline & & PGT-PSDC-PTdoB & PSL \\
\hline & Dep. Estadual & PFL-PSL & PPB \\
\hline \multirow{10}{*}{2002} & \multirow{6}{*}{$\begin{array}{c}\text { Dep. Federal } \\
\text { e } \\
\text { Dep. Estadual }\end{array}$} & PT-PCdoB-PL-PMN & PMDB \\
\hline & & PDT-PTB & PSDB \\
\hline & & PPS-PV-PSDC & PSTU \\
\hline & & PSB-PSD & \\
\hline & & PAN-PGT-PHS-PSC-PTC-PTN & \\
\hline & & PRTB-PST-PTdoB & \\
\hline & Dep. Federal & PPB-PFL-PSL & \\
\hline & \multirow{3}{*}{ Dep. Estadual } & & PPB \\
\hline & & & PFL \\
\hline & & & PSL \\
\hline
\end{tabular}

Fonte: TRE/SC. 


\section{Referências Bibliográficas}

AMES, B. Os entraves à democracia no Brasil. Rio de Janeiro: Ed. FGV, 2003.

BOBBIO, N. Direita e esquerda. São Paulo: Ed. UNESP, 1995.

CARREIRÃO, Y. Identificação ideológica e voto para presidente. Opinião Pública, v. 8, n. 1, p. 54.79, maio 2002.

CASTAÑEDA, J. Utopia desarmada. São Paulo: Cia. das Letras, 1994.

FERNANDES, L. Muito barulho por nada? Dados, v. 38, n. 1, p. 107-143, 1995.

FIGUEIREDO, A.; LIMONGI, F. Executivo e Legislativo na nova ordem constitucional. Rio de Janeiro: Ed. FGV, 1999.

FIGUEIREDO, M. A lei de ferro da competição eleitoral: a aritmética eleitoral. Cadernos de Conjuntura, Rio de Janeiro, IUPERJ, n. 50, jul. 1994.

FREIRE, V. T. Urubus políticos e partidos. Folha de S. Paulo, São Paulo, 26 set. 2005. Opinião, p. 2.

KINZO, M. D. O quadro partidário e a constituinte. In: LAMOUNIER, B. (org.) De Geisel a Collor: o balanço da transição. São Paulo: IDESP / Sumaré, 1990. 1993.

Radiografia do quadro partidário brasileiro. São Paulo: Fundação Konrad Adenauer,

LIMA Jr., O. B. Partidos políticos brasileiros - 45 a 64. Rio de Janeiro: Graal, 1983.

MAINWARING, S. Sistemas partidários em novas democracias: o caso do Brasil. Porto Alegre/Rio de Janeiro: Mercado Aberto/Ed. FGV, 2001.

MELO, C. R. Retirando as cadeiras do lugar: migração partidária na Câmara dos Deputados (19852002). Belo Horizonte: Ed. UFMG, 2004. 
NICOLAU, J. M. Breves comentários sobre as eleições de 1994 e o quadro partidário.

Cadernos de Conjuntura, Rio de Janeiro, IUPERJ, n. 50, julho 1994. Multipartidarismo e democracia. Rio de Janeiro: Ed. FGV, 1996.

NOVAES, C. A. M. Dinâmica institucional da representação - individualismo e partidos na Câmara dos Deputados. Novos Estudos CEBRAP, São Paulo, n. 38, p. 99.147, março 1994.

PANEBIANCO, A. Political parties: organization and power. Cambridge: Cambridge University Press, 1988.

REIS, F. W. Direita e esquerda e o eleitor brasileiro. In: REIS, F. W. Tempo presente: do MDB a FHC. Belo Horizonte: Ed. UFMG, 2002.

RODRIGUES, L. M. Partidos, ideologia e composição social. São Paulo: Edusp, 2002.

SANTOS, W. G. Crise e castigo: partidos e generais na política brasileira. São Paulo: Vértice, 1987.

SCHMITT, R. Migração partidária e reeleição na Câmara dos Deputados. Novos Estudos Cebrap, n. 54, 1999.

SCHWARTZMAN, S. Vinte años de democracia representativa en Brasil. Revista Latino Americana de Ciência Política, v. 2, n. 1, 1971.

SINGER, A. Esquerda e direita no eleitorado brasileiro. São Paulo: Edusp, 2000.

SOARES, G. A. D. Alianças e coligações eleitorais: notas para uma teoria. Revista Brasileira de Estudos Políticos, n. 17, julho 1964.

SoUZA, M. C. C. Estado e partidos políticos no Brasil. São Paulo: Alfa-Ômega, 1976.

TAVARES, J. A. G. Reforma política e retrocesso democrático. Porto Alegre: Mercado Aberto, 1998. 